\title{
Numerical Simulation of the Combined Effects of Low Salinity Water and Alkaline-Surfactant-Polymer Flooding
}

\author{
Eric Broni-Bediako, Eric Thompson Brantson, Kwabena Antwi Asante \\ Department of Petroleum and Natural Gas Engineering, School of Petroleum Studies, University of Mines and Technology, Tarkwa, Ghana \\ Email address: \\ ebroni-bediako@umat.edu.gh (E. Broni-Bediako), etbrantson@umat.edu.gh (E. T. Brantson), kasante292@yahoo.com (K. A. Asante)
}

\section{To cite this article:}

Eric Broni-Bediako, Eric Thompson Brantson, Kwabena Antwi Asante. Numerical Simulation of the Combined Effects of Low Salinity Water and Alkaline-Surfactant-Polymer Flooding. International Journal of Oil, Gas and Coal Engineering. Vol. 9, No. 4, 2021, pp. 46-58.

doi: 10.11648/j.ogce.20210904.11

Received: July 17, 2021; Accepted: July 26, 2021; Published: August 2, 2021

\begin{abstract}
Low Salinity Water (LSW) and Alkaline-Surfactant-Polymer (ASP) flooding are emerging enhanced oil recovery methods that help recover oil from the reservoir after primary and secondary recovery processes. Experimental studies on LSW and ASP flooding have indicated potential in additional oil recovery. In this paper, numerical simulation was performed to study the combined effects of LSW and ASP flooding. A heterogenous reservoir initially saturated with oil and water was modelled using Eclipse. The wells were completed with an inverse five-spot pattern and the production life of the reservoir was taken to be five years. The results showed that LSW flooding using a salt concentration of $1000 \mathrm{ppm}$ achieved a higher oil recovery than conventional (high salinity) water flooding with a salt concentration of $35000 \mathrm{ppm}$. The oil recovery for conventional water flooding was $59.5 \%$ and that of low salinity flooding was $64.1 \%$. The overall oil recovery for LSW combined with alkaline, surfactant and polymer flooding were $64.1 \%, 70.5 \%$ and $62.6 \%$, respectively. The model indicated an increase in overall oil recovery of $91 \%$ when alkaline, surfactant and polymer were combined and injected as the same slug as opposed to the injection of the chemicals individually. This was attributed to the synergy of the chemicals. The alkaline and the surfactant reduce the interfacial tension between the oil and water and the polymer improves the mobility ratio thereby increasing sweep efficiency.
\end{abstract}

Keywords: Alkaline, Low Salinity, Polymer, Surfactant

\section{Introduction}

Oil production traditionally runs through series of stages namely primary, secondary, and tertiary recovery process. In the primary production stage, oil is recovered under the natural driving mechanism present in the reservoir or some artificial lift tools, such as gas lift or pumps. Water or gas is injected to the aquifer or gas cap respectively during the secondary stage to supplement the reservoir pressure and to displace the oil and improve recovery. The selected secondary technique generally follows the primary recovery, but it can also be conducted concurrently with the primary process. A high oil saturation is usually rendered immobile (residual oil saturation) after applying primary and secondary oil recovery methods [1]. According to Behnoudfar et al. [2], the remaining oil is approximately two-third of the Original Oil in Place (OOIP) after applying primary and secondary oil recovery methods. This happens because the oil is entrapped in the pore spaces due to capillary and viscous forces or the oil is bypassed as a result of unfavourable mobility ratio between the oleic and the aqueous phase. Tertiary recovery processes aim at reducing residual oil saturation by introducing thermal energy or special fluids such as chemicals and miscible gases to the reservoir. Very tight and highly viscous reservoirs can only produce oil by applying tertiary recovery means and, in such cases, do not follow the chronological production stages [3].

Historically, water injection has been used to supplement reservoir pressure and little attention given on the salinity of the injected water. However, in recent years, studies have been conducted on the effects of altering the salinity of the injected water. Most of the results showed a high oil recovery could be achieved when the salinity of the injected water is much lower than the formation water [4] and thus a potential for low-salinity water injection as an Enhanced Oil Recovery (EOR) method. Experimental works have also been done on combining LSW flooding with other proven chemical EOR methods. Alagic and Skauge in their work indicated an 
increase in oil recovery when low-salinity brine injection was combined with surfactant flooding in mixed-wet sandstone cores [5].

Alkaline-Surfactant-Polymer (ASP) flooding uses a combination of alkaline, surfactant and polymer as the injection slug for further improvement on oil recovery [6]. It has been demonstrated in experimental works as an effective EOR method with recovery factor up to $98 \%$ of the OOIP [7]. The combined chemicals improve oil recovery by reducing interfacial tension between the oil and the displacing fluid and also providing a favourable mobility ratio to improve macroscopic sweep efficiency. During ASP flooding, polymer is used for mobility control, surfactant reduces the interfacial tension and subsequently the residual oil saturation and alkaline generates surfactant in situ as it reacts with naphthenic acids in the crude oil $[8,9]$. The synergy of the individual chemicals increases oil recovery substantially and makes ASP flooding cost effective as less of the chemicals are used when they are injected in the same slug. Global demand and consumption forecast of oil and gas continue to grow. Moreover, there is significant depletion of conventional resources and high cost coupled with high uncertainties involved in exploiting unconventional resources. EOR methods such as LSW and ASP flooding will play a key role to produce the oil reserves which are left behind after primary recovery and application of secondary recovery processes. Experimental works using cores in low salinity and ASP flooding which have been documented in literature [10, 11], have shown improvement in displacement efficiency yielding high oil recovery. Much work is needed to build upon the laboratory studies of this synergistic technique to establish it as a reliable EOR method. Thus, this research seeks to move a step further by utilising numerical simulation to study the combined effects of low salinity and ASP flooding. It is a fairly new recovery process and has the potential to yield an increase in oil recovery as a result of the synergy of the recovery techniques.

\section{Reservoir Description and Modelling}

An oil reservoir was modelled using Eclipse. The reservoir measured roughly $7400 \mathrm{ft}, 7400 \mathrm{ft}$ and $28 \mathrm{ft}$ in the X, Y and Z directions, respectively. A total of 12150 grid blocks were used corresponding to forty-five grid blocks in both the $\mathrm{X}$ and $\mathrm{Y}$ directions and six grid blocks in the Z-direction. In this simulation, flexible grids, precisely corner point geometry was used. This approach permitted a better representation of reservoir geological features and reservoir description, especially for heterogeneities and wells as opposed to traditional cartesian grids. The reservoir was heterogenous with variations in both porosity and permeability. Reservoir porosity had values ranging between $9 \%$ and $30 \%$, also reservoir permeability varied in all directions with the vertical permeability generally lower than the horizontal permeability. The horizontal permeability ranged between $10 \mathrm{mD}$ to $70 \mathrm{mD}$. On the other hand, the vertical permeability ranged between $0.7 \mathrm{mD}$ to $2 \mathrm{mD}$. The active fluid phases in the model were water and oil. Figures 1 to 3 show the porosity and permeability variations in the reservoir model.

Well completion was implemented once the model was set up. The inverse five spot pattern was used in the simulation and both the production and injection wells were perforated in all six layers of the model. All the five wells were vertical wells. The well pattern yielded an effective areal sweep efficiency. This is because, with the injection well situated at the centre of the reservoir, the injected fluid swept the oil all the way to the corners of the reservoir where the production wells were located improving oil recovery.

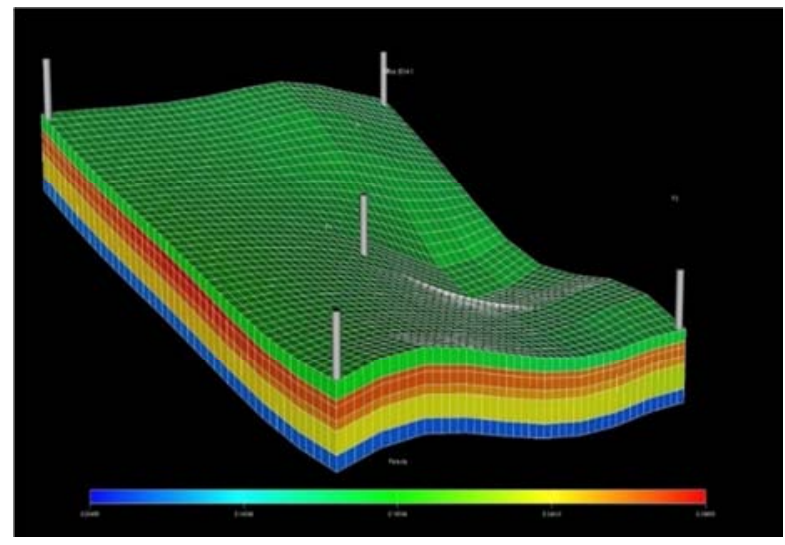

Figure 1. Porosity of the Reservoir Model.

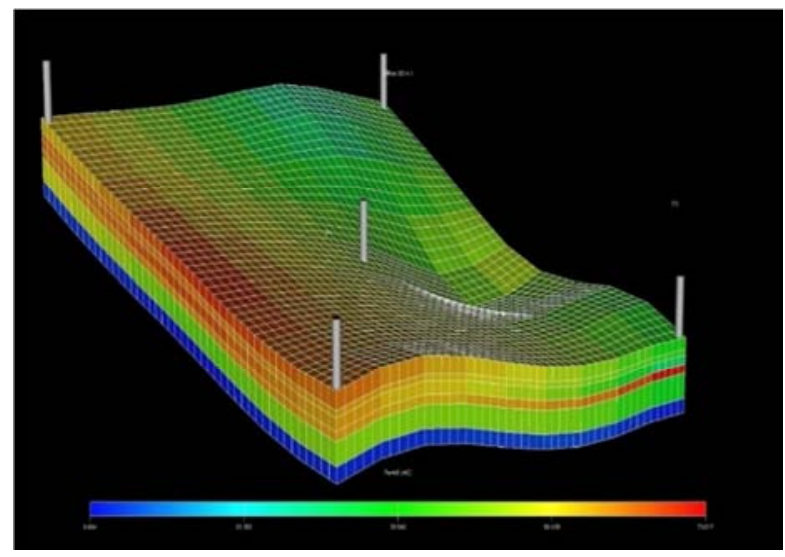

Figure 2. Permeability in the X-direction of the Reservoir Model.

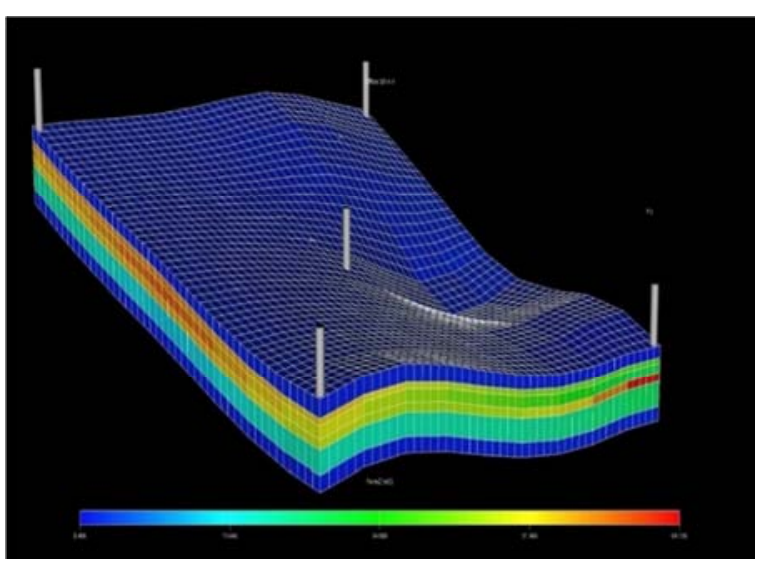

Figure 3. Permeability in the Z-direction of the Reservoir Model. 


\subsection{Low Salinity Water Flooding Modelling}

The concentration of salt in the aqueous phase changed the water density and the viscosity. The distribution of brine was modelled by using a mass conservation equation for the salt concentration in each grid block. Brine was assumed to exist in the aqueous phase and was modelled internally as a water phase tracer using Equation 1 [10].

$$
\frac{\mathrm{d}}{\mathrm{dt}}\left(\frac{\mathrm{VS}_{\mathrm{w}} \mathrm{C}_{\mathrm{s}}}{\mathrm{B}_{\mathrm{w}}}\right)=\sum\left[\frac{\mathrm{Tk}_{\mathrm{rw}}}{\mathrm{B}_{\mathrm{w}} \mu_{\mathrm{seff}}}\left(\delta \mathrm{P}_{\mathrm{w}}-\rho_{\mathrm{w}} \mathrm{gD}_{\mathrm{z}}\right)\right] \mathrm{C}_{\mathrm{s}}+\mathrm{Q}_{\mathrm{w}} \mathrm{C}_{\mathrm{s}}
$$

where:

$\rho_{\mathrm{w}}$ denotes the water density.

$\sum$ denotes the sum over neighbouring cells.

$\mathrm{C}_{\mathrm{s}}$ denotes the salt concentration in the aqueous phase.

$\mu_{\text {seff }}$ denotes the effective viscosity of the salt.

$D_{z}$ is the cell centre depth.

$B_{w}$ is the water formation volume factor.

$\mathrm{T}$ is the transmissibility.

$\mathrm{k}_{\mathrm{rw}}$ is the water relative permeability.

$\mathrm{S}_{\mathrm{w}}$ is the water saturation.

$\mathrm{V}$ is the block pore volume.

$\mathrm{Q}_{\mathrm{w}}$ is the water production rate.

$\mathrm{P}_{\mathrm{w}}$ is the water pressure; and

$\mathrm{g}$ is the acceleration due to gravity.

In modelling LSW flooding, it was assumed that the LSW induced a wettability change in the formation which resulted in a change in relative permeability of the fluids. The low salinity option in Eclipse enabled modelling of low salt water. This option allowed the modification of saturation and relative permeability end points for water and oil phases as function of the salt concentration and oil-water capillary pressure. Therefore, two sets of water/oil saturation functions were used in the modelling. Given two sets of saturation functions, one for low salinity and one for high salinity, the saturation end points were modelled as presented in Equations 2 to 5 [12].

$$
\begin{gathered}
\mathrm{S}_{\mathrm{wco}}=\mathrm{F}_{1} \mathrm{~S}_{\mathrm{wco}}^{\mathrm{L}}+\left(1-\mathrm{F}_{1}\right) \mathrm{S}_{\mathrm{wco}}^{\mathrm{H}} \\
\mathrm{S}_{\mathrm{wcr}}=\mathrm{F}_{1} \mathrm{~S}_{\mathrm{wcr}}^{\mathrm{L}}+\left(1-\mathrm{F}_{1}\right) \mathrm{S}_{\mathrm{wcr}}^{\mathrm{H}} \\
\mathrm{S}_{\mathrm{wmax}}=\mathrm{F}_{1} \mathrm{~S}_{\mathrm{wmax}}^{\mathrm{L}}+\left(1-\mathrm{F}_{1}\right) \mathrm{S}_{\mathrm{wmax}}^{\mathrm{H}} \\
\mathrm{S}_{\mathrm{owcr}}=\mathrm{F}_{1} \mathrm{~S}_{\mathrm{owcr}}^{\mathrm{L}}+\left(1-\mathrm{F}_{1}\right) \mathrm{S}_{\mathrm{owcr}}^{\mathrm{H}}
\end{gathered}
$$

where:

$F_{1}$ is the function of the salt concentration.

$\mathrm{S}_{\mathrm{wco}}$ is the connate water saturation.

$\mathrm{S}_{\mathrm{wcr}}$ is the critical water saturation.

$\mathrm{S}_{\mathrm{wmax}}$ is the maximum water saturation.

$\mathrm{S}_{\text {owcr }}$ is the critical oil saturation in water.

$\mathrm{H}$ is the high salinity index; and

$\mathrm{L}$ is the low salinity index.

The F1 factor is a function of brine concentration, and it is provided as a look-up table. Then, the relative permeabilities for water and oil, and oil-water capillary pressure are first found by look-up table at the scaled saturations and then interpolated similarly as presented in Equations 6 to 8 [12].

$$
\begin{gathered}
\mathrm{k}_{\mathrm{rw}}=\mathrm{F}_{1} \mathrm{k}_{\mathrm{rw}}^{\mathrm{L}}+\left(1-\mathrm{F}_{1}\right) \mathrm{k}_{\mathrm{rw}}^{\mathrm{H}} \\
\mathrm{k}_{\mathrm{ro}}=\mathrm{F}_{1} \mathrm{k}_{\mathrm{ro}}^{\mathrm{L}}+\left(1-\mathrm{F}_{1}\right) \mathrm{k}_{\mathrm{ro}}^{\mathrm{H}} \\
\mathrm{P}_{\text {cow }}=\mathrm{F}_{2} \mathrm{P}_{\text {cow }}^{\mathrm{L}}+\left(1-\mathrm{F}_{2}\right) \mathrm{P}_{\text {cow }}^{\mathrm{H}}
\end{gathered}
$$

where:

$\mathrm{F}_{2}$ is a function of the salt concentration.

$\mathrm{k}_{\mathrm{rw}}$ is the water relative permeability.

$\mathrm{k}_{\mathrm{ro}}$ is the oil relative permeability; and

$\mathrm{P}_{\text {cow }}$ is the oil-water capillary pressure.

With the low salt option being active, the weighting factors for the low salinity saturations functions were inputted as a function of the salt concentration. The weighting factors were denoted by F1 and F2. F1 was the weighting factor for the low salinity saturation endpoints and the relative permeabilities interpolation while F2 was the weighting factor for the low salinity capillary pressure interpolation. A value of 0 implied that only the high saturation functions will be used and a value of 1 implied that only low salinity saturation functions will be used. The weighting factors indicated the effectiveness of salinity.

\section{Modelling High and Low Salinity Curves}

Since both water and oil were the active fluid phases present in the reservoir, the SWOF keyword, defined in the PROPS section was used to input tables of water relative permeability, oil-in-water relative permeability and water-oil capillary pressure as functions of the water saturation. Each table consisted of four columns of data. High and low salinity relative permeability tables were defined here. Figure 4 shows the oil and water relative permeability curves for high salinity and low salinity as a function of water saturation used in the simulation.

\subsection{Alkaline Flooding Modelling}

Alkaline flooding involves introducing alkaline into the reservoir to react with the naphthenic acids to produce surfactants in-situ that reduces the interfacial tension and consequently release oil from the rock pores. Alkaline injection is usually effective when the acidic content of the oil is relatively high. When used together with surfactant and polymer such in the case of ASP flooding, alkaline can reduce the adsorption of both surfactant and polymer (which are expensive chemicals) on the rock surface. Alkaline therefore improves the effectiveness the surfactant and polymer injection [11]. In this model, alkaline was assumed to exist only in the aqueous phase as a concentration in a water injection process. The distribution of the injected alkaline was modelled by the conservation Equation 9 [10]:

$$
\begin{array}{r}
\frac{\mathrm{d}}{\mathrm{dt}}\left(\frac{\mathrm{VS_{w }} \mathrm{C}_{\mathrm{a}}}{\mathrm{B}_{\mathrm{r}} \mathrm{B}_{\mathrm{w}}}\right)+\frac{\mathrm{d}}{\mathrm{dt}}\left(\mathrm{V} \rho_{\mathrm{r}} \mathrm{C}_{\mathrm{a}}^{\mathrm{a}} \frac{1-\varphi}{\varphi}\right)= \\
\sum\left[\frac{\mathrm{Tk}}{\mathrm{B}_{\mathrm{w}} \mu_{\mathrm{seff}}}\left(\delta \mathrm{P}_{\mathrm{w}}-\rho_{\mathrm{w}} \mathrm{gD}_{\mathrm{z}}\right)\right] \mathrm{C}_{\mathrm{a}}+\mathrm{Q}_{\mathrm{w}} \mathrm{C}_{\mathrm{a}}
\end{array}
$$

where:

$\rho_{\mathrm{w}}, \rho_{\mathrm{r}}$ denotes the water and rock density respectively.

$\sum$ denotes the sum over neighbouring cells.

$\mathrm{C}_{\mathrm{a}}$ denotes the alkaline concentration. 
$\left(C^{\mathrm{a}}\right)_{\mathrm{a}}$ denotes the adsorbed alkaline concentration.

$\mu_{\text {seff }}$ denotes the effective viscosity of the salt.

$\mathrm{D}_{\mathrm{z}}$ is the cell centre depth.

$B_{w}, B_{r}$ is the water and rock formation volume factor respectively.

$\mathrm{T}$ is the transmissibility.

$\mathrm{k}_{\mathrm{rw}}$ is the water relative permeability.

$\mathrm{S}_{\mathrm{w}}$ is the water saturation.

$\mathrm{V}$ is the block pore volume.

$\mathrm{Q}_{\mathrm{w}}$ is the water production rate.

$\mathrm{P}_{\mathrm{w}}$ is the water pressure; and

$\mathrm{g}$ is the acceleration due to gravity.

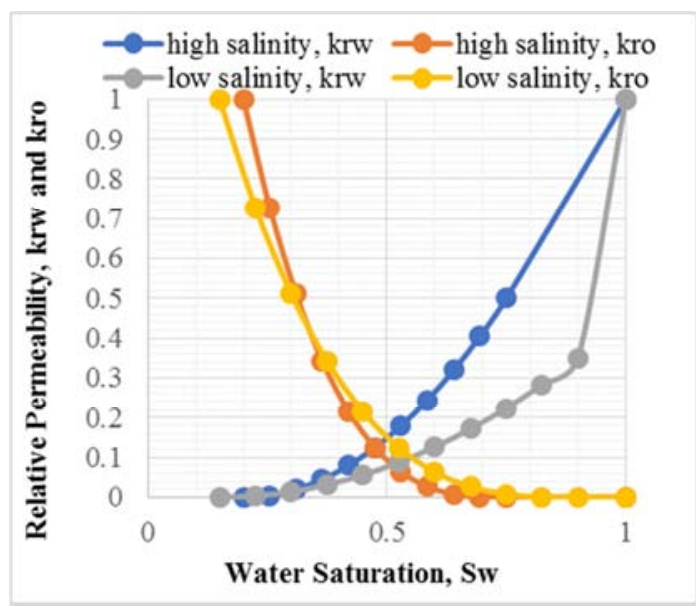

Figure 4. Water and Oil Relative Permeability Curves for Low and High Salinity.

\subsubsection{Alkaline Adsorption Modelling}

The ALKADS keyword in the PROPS section described the adsorption of alkaline by the rock formation. It consisted of two columns of data: the local alkaline concentration in the solution surrounding the rock and the corresponding saturated concentration of alkaline adsorbed by the rock formation. In Eclipse, alkaline adsorption was assumed to be instantaneous. The ALKROCK keyword, which was also specified in the PROPS section, was used to determine whether desorption of the alkaline was prevented or allowed. If desorption was prevented, then the adsorbed alkaline concentration may not have decreased with time. Meaning, the alkaline effect on polymer or surfactant adsorption was assumed to be permanent. Oppositely, if desorption was allowed, then the alkaline adsorption isotherm would have been retraced whenever the local alkaline concentration in the solution decreased. This model assumed no alkaline desorption occurred. Table 1 shows the alkaline adsorption as a function of the alkaline concentration used in this study.

Table 1. Alkaline Adsorption as a Function of Alkaline Concentration [12].

\begin{tabular}{ll}
\hline Alkaline Concentration (lb/stb) & Alkaline Adsorbed (lb/lb) \\
\hline 0.00 & 0.000000 \\
1.05 & 0.000005 \\
2.10 & 0.000007 \\
3.15 & 0.000008 \\
3.51 & 0.000009 \\
\hline
\end{tabular}

\subsubsection{Alkaline Effect on Water-Oil Surface Tension}

The effect of alkaline on the water-oil surface tension was modelled as a combined effect with surfactant by modifying the water-oil surface tension with the Equation 10 [10].

$$
\sigma_{\text {wo }}=\sigma_{\text {wo }}\left(\mathrm{C}_{\text {surf }}\right) \mathrm{A}_{\mathrm{st}}\left(\mathrm{C}_{\mathrm{alk}}\right)
$$

where:

$\sigma_{\mathrm{wo}}\left(\mathrm{C}_{\text {surf }}\right)$ is the surface tension at surfactant concentration and zero alkaline concentration; and

$\mathrm{A}_{\mathrm{st}}\left(\mathrm{C}_{\mathrm{alk}}\right)$ is the surface tension multiplier at alkaline concentration.

The ALSURFST keyword, which was specified in the PROPS section, was used to provide tables of surface tension multipliers as a function of the alkaline concentration. Each table consisted of two columns of data: the local alkaline concentration and the corresponding surface tension multiplier. The ALSURFST is shown Table 2.

Table 2. Water-oil Surface Tension Multiplier as a Function of Alkaline Concentration [12].

\begin{tabular}{ll}
\hline Alkaline Concentration (lb/stb) & Water-oil Surface Tension Multiplier \\
\hline 0.0 & 1.0 \\
0.1 & 0.9 \\
0.2 & 0.8 \\
0.5 & 0.7 \\
\hline
\end{tabular}

2.2.3. Alkaline Effect on Surfactant and Polymer Adsorption

Alkaline can reduce the adsorption of both surfactant and polymer on the rock surface. In Eclipse, this phenomenon was modelled by modifying the mass of the adsorbed surfactant or polymer by using Equation 11 [10]:

$$
\mathrm{V} \rho_{\mathrm{r}} \mathrm{C}_{\mathrm{s}, \mathrm{p}}^{\mathrm{a}} \frac{1-\phi}{\phi} \mathrm{A}_{\mathrm{ad}}\left(\mathrm{C}_{\mathrm{alk}}\right)
$$

where:

$\mathrm{V}$ is the pore volume of the cell.

$\phi$ is the porosity.

$\rho_{\mathrm{r}}$ is the mass density of the rock.

$\mathrm{C}_{(\mathrm{s}, \mathrm{p})}{ }^{\mathrm{a}}$ is the surfactant/polymer adsorbed concentration; and

$\mathrm{A}_{\mathrm{ad}}\left(\mathrm{C}_{\mathrm{alk}}\right)$ is the adsorption multiplier at alkaline concentration.

In the case whereby the alkaline is assumed to be adsorbed irreversibly, by preventing desorption using the ALROCK keyword, its effect on surfactant/polymer adsorption is assumed to be irreversible as well. Using the notations in Equation 11, the mass of adsorbed surfactant or polymer becomes [10]:

$$
\mathrm{V} \rho_{\mathrm{r}} \mathrm{C}_{\mathrm{s}, \mathrm{p}}^{\mathrm{a}} \frac{1-\phi}{\phi} \mathrm{A}_{\mathrm{ad}}\left(\mathrm{C}_{\mathrm{alkmax}}\right)
$$

where: $\mathrm{C}_{\text {alkmax }}$ is the maximum alkaline concentration reached in the block, corresponding to the actual effect on surfactant/polymer adsorption.

The ALSURFAD keyword in the PROPS section comprised tables of surfactant adsorption multipliers as a function of the alkaline concentration. The ALSURFAD is shown in Table 3. 
Table 3. Surfactant Adsorption Multiplier as a Function of Alkaline Concentration [12].

\begin{tabular}{ll}
\hline Alkaline Concentration (lb/stb) & Surfactant Adsorption Multiplier \\
\hline 0.0 & 1.00000 \\
0.1 & 0.99995 \\
0.2 & 0.99500 \\
0.5 & 0.50000 \\
\hline
\end{tabular}

\subsection{Surfactant Flooding Modelling}

Surfactant flooding offers a way of recovering the residual oil by utilizing surface-acting agents to adsorb onto the oil-water interface to reduce the interfacial tension. A very low oil-water interfacial tension reduces the capillary pressure which means water can displace the trapped oil. Surfactant adsorption by the formation rock influences the effectiveness of the surfactant injection process. If the adsorption is very high, then large quantities of expensive surfactants will be required to produce a small quantity of additional oil [13-15].

The surfactant model was activated by specifying SURFACT keyword in the RUNSPEC section. The surfactant was assumed to exist only in the aqueous phase as a concentration in a water injection process and the distribution of injected surfactant was modelled in Eclipse by solving a conservation equation for surfactant within the aqueous phase.

\subsubsection{Surfactant Effect on Water-Oil Surface Tension}

This effect was modelled by supplying tables of water-oil surface tension as a function of surfactant concentration in the water. The SURFST keyword in the PROPS section was used to supply the tables. Table 4 shows the SURFST.

Table 4. Water-oil Surface Tension as a Function of Surfactant Concentration [12].

\begin{tabular}{ll}
\hline $\begin{array}{l}\text { Surfactant Concentration } \\
\text { (lb/stb) }\end{array}$ & Water-oil Surface Tension (lbf/in) \\
\hline 0.0 & 0.050000 \\
1.0 & 0.000006 \\
30.0 & 0.000006 \\
\hline
\end{tabular}

\subsubsection{Surfactant Solution Viscosity Function}

The keyword SURFVISC in the PROPS section comprised tables of surfactant viscosity functions. It described the effect on the viscosity of pure water of increasing the concentration of surfactant in solution. The keyword consisted of two columns of data: the surfactant concentration in the solution and the solution water viscosity at this surfactant concentration and the reference pressure. The water-surfactant solution viscosity is calculated using Equation (13) [10].

$$
\mu_{\mathrm{ws}}\left(\mathrm{C}_{\text {surf }}, \mathrm{P}\right)=\mu_{\mathrm{w}}(\mathrm{P}) \frac{\mu_{\mathrm{s}}\left(\mathrm{C}_{\text {surf }}\right)}{\mu_{\mathrm{w}}\left(\mathrm{P}_{\text {ref }}\right)}
$$

\subsubsection{Surfactant Capillary Desaturation Function}

The SURFCAPD keyword data comprised tables of surfactant capillary desaturation functions. The desaturation function described the transition between immiscible conditions (low surfactant concentration) and miscible conditions (high surfactant concentration) as a function of the dimensionless capillary number. The table consisted of two columns of data: the log of the capillary number and the miscibility function at the value of the log capillary number. The SURFCAPD data is shown in Table 5.

Table 5. Log of Capillary Number versus Miscibility Functio [12].

\begin{tabular}{ll}
\hline Log of Capillary Number & Miscibility Function \\
\hline-9 & 0.0 \\
-4.5 & 0.0 \\
-2 & 1.0 \\
10 & 1.0 \\
\hline
\end{tabular}

\subsubsection{Surfactant Adsorption Modelling}

In this study, the adsorption of surfactant was assumed to be instantaneous, and the quantity adsorbed is a function of the surrounding surfactant concentration. The quantity of adsorbed surfactant onto the formation rock was calculated as presented in Equation 14 [10]:

$$
\begin{aligned}
& \text { Mass of adsorbed surfactant }=\text { PORV } \\
& \qquad \text { CA(C_surf })
\end{aligned}
$$

where:

PORV is the pore volume of the cell.

$\phi$ is the porosity.

$\mathrm{MD}$ is the mass density of the rock; and

$\mathrm{CA}\left(\mathrm{C}_{\text {surf }}\right)$ is the adsorption isotherm as a function of local surfactant concentration in solution.

The SURFADS keyword in the PROPS section comprised tables of surfactant adsorption functions, describing the adsorption of surfactant by the rock formation. It consisted of two columns of data: the local surfactant concentration in the solution surrounding the rock and the corresponding saturated concentration of the surfactant adsorbed by the rock formation. The SURFROCK keyword, also in the PROPS section comprised tables specifying the rock properties required for the surfactant model. It contained two columns of data: the adsorption index for the rock type and the mass density of the rock type at reservoir conditions. Possible values for the adsorption index are 1 and 2 . If the value of 1 is selected, then the surfactant adsorption isotherm is retraced whenever the local surfactant concentration in the solution decreases. Alternatively, if the value 2 is selected, then no surfactant desorption occurs. The SURFADS and SURFROCK data are given in Tables 6 and 7 .

Table 6. Surfactant Adsorption as a Function of Surfactant Concentration [12].

\begin{tabular}{ll}
\hline $\begin{array}{l}\text { Surfactant Concentration } \\
\text { (lb/stb) }\end{array}$ & $\begin{array}{l}\text { Saturated Concentration of Surfactant } \\
\text { Adsorbed by the Rock (lb/lb) }\end{array}$ \\
\hline 0.0 & 0.0000 \\
1.0 & 0.0005 \\
30.0 & 0.0005 \\
\hline
\end{tabular}

Table 7. Adsorption Index versus Mass Density of Rock formation [12].

\begin{tabular}{ll}
\hline Adsorption index & Mass density of rock $(\mathbf{l b} / \mathbf{r b})$ \\
\hline 1 & 2650 \\
2 & 2650 \\
\hline
\end{tabular}

\subsection{Polymer Flooding Modelling}

The overall mechanism of oil recovery by polymer flooding 
is to increase the water viscosity, decrease the effective permeability to water due to polymer retention; and decrease water-oil mobility ratio thereby improving the macroscopic sweep efficiency [16-18].

The polymer option was activated by specifying POLYMER in the RUNSPEC section. As salt-sensitivity for polymer was required in this model, the keyword BRINE was also activated. The flow of the polymer solution through the formation was assumed to have no influence on the flow of the hydrocarbon phase. The standard black oil equations were therefore used to describe the hydrocarbon phase in the model. The water, polymer and brine equations used in the model are presented in Equations 15 and 17, respectively [10].

$$
\begin{gathered}
\frac{d}{d t}\left(\frac{V{ }_{w}}{B_{r} B_{w}}\right)=\sum\left[\frac{T k_{r w}}{B_{w} \mu_{w} \text { eff } R_{k}}\left(\delta P_{w}-\rho_{w} g D_{z}\right)\right]+Q_{w} \\
\frac{d}{d t}\left(\frac{V^{*} S_{w} C_{p}}{B_{r} B_{w}}\right)+\frac{d}{d t}\left(V \rho_{r} C_{p}^{a} \frac{1-\phi}{\phi}\right)=\sum\left[\frac { T k _ { r w } } { B _ { w } \mu _ { p } \text { eff } R _ { k } } \left(\delta P_{w}-\right.\right. \\
\left.\left.\rho_{w} g D_{z}\right)\right] C_{p}+Q_{w} C_{p} \\
\frac{d}{d t}\left(\frac{V_{w_{w}} C_{n}}{B_{r} B_{w}}\right)=\sum\left[\frac{T k_{r w} C_{n}}{B_{w} \mu_{s} \text { eff } R_{k}}\left(\delta P_{w}-\rho_{w} g D_{z}\right)\right]+Q_{w} C_{n}
\end{gathered}
$$

and

$$
\mathrm{V}^{*}=\mathrm{V}\left(1-\mathrm{S}_{\mathrm{dpv}}\right)
$$

where:

$\mathrm{S}_{\mathrm{dpv}}$ denotes the dead pore space within each grid cell.

$\mathrm{C}_{\mathrm{p}}{ }^{\mathrm{a}}$ denotes the polymer adsorption concentration.

$\rho_{\mathrm{r}}$ denotes the mass density of the rock formation.

$\phi$ denotes the porosity.

$\rho$ w denotes the water density.

$\sum$ denotes sum over neighbouring cells.

$\mathrm{R}_{\mathrm{k}}$ denotes the relative permeability reduction factor for the aqueous phase due to polymer retention.

$\mathrm{C}_{\mathrm{p}}, \mathrm{C}_{\mathrm{n}}$ denotes the polymer and salt concentrations respectively in the aqueous phase.

$\mu_{\text {aeff }}$ denotes the effective viscosity of the water $(a=w)$, polymer $(\mathrm{a}=\mathrm{p})$ and salt $(\mathrm{a}=\mathrm{s})$.

$D_{z}$ is the cell centre depth.

$\mathrm{B}_{\mathrm{r}}, \mathrm{B}_{\mathrm{w}}$ are the rock and water formation factor volumes.

$\mathrm{T}$ is the transmissibility.

$\mathrm{k}_{\mathrm{rw}}$ is the water relative permeability.

$\mathrm{S}_{\mathrm{w}}$ is the water saturation.

$\mathrm{V}$ is the block pore volume.

$\mathrm{Q}_{\mathrm{w}}$ is the water production rate.

$\mathrm{P}_{\mathrm{w}}$ is the water pressure; and

$\mathrm{g}$ is the acceleration due to gravity.

The model assumed that the density and formation volume factor of the aqueous phase were independent of the polymer and salt concentrations. The polymer solution, reservoir brine and the injected water were represented in the model as miscible components in the aqueous phase, where the degree of mixing was specified through the viscosity terms in the conservation equations.

\subsubsection{Polymer Adsorption Modelling}

In this model, the polymer was assumed to be adsorbed instantaneously. The effect of polymer adsorption was to create a stripped water bank at the leading edge of the slug during the flooding process. Desorption effect may occur as the slug passes in the rock formation. If polymer desorption is not allowed, then the adsorbed polymer concentration does not decrease with time. Alternatively, if polymer desorption is allowed then each grid block retraces the adsorption isotherm as the alkaline concentration rises and falls in the grid cell. The PLYROCK keyword was used to specify this effect. The PLYADS keyword in the PROPS section comprised tables of polymer adsorption functions describing the adsorption of polymer by the rock formation. The table consisted of two columns of data: the local polymer concentration in the solution surrounding the rock and the corresponding saturated concentration of polymer adsorbed by the rock formation (the mass of adsorbed polymer per unit mass of rock). The PLYADS data is given in Table 8.

Table 8. Polymer Adsorption as a Function of Polymer Concentration [12].

\begin{tabular}{ll}
\hline $\begin{array}{l}\text { Polymer Concentration } \\
\text { (lb/stb) }\end{array}$ & $\begin{array}{l}\text { Saturated Concentration of Polymer } \\
\text { Adsorbed by the Rock (lb/lb) }\end{array}$ \\
\hline 0.0 & 0.000 \\
20.0 & 0.010 \\
70.0 & 0.010 \\
\hline
\end{tabular}

\subsubsection{Polymer Effect on Fluid Viscosity}

The viscosity terms used in the fluid flow equations contained the effects of a change in the viscosity of the aqueous phase due to the presence of polymer and salt in the solution. However, to incorporate the effects of physical dispersion at leading edge of the slug and the fingering effects at the rear edge of the slug, the fluid components were allocated effective viscosity values that were calculated using the Todd-Longstaff technique. The effective polymer viscosity is given in Equation 18 as [10]:

$$
\mu_{\mathrm{p}, \mathrm{eff}}=\mu_{\mathrm{m}}\left(\mathrm{C}_{\mathrm{p}}\right)^{\omega} \cdot \mu_{\mathrm{p}}^{1-\omega}
$$

where:

$\mu_{\mathrm{m}}\left(\mathrm{C}_{\mathrm{p}}\right)$ is the viscosity of the fully mixed polymer solution as an increasing function of the polymer concentration in solution.

$\mu_{\mathrm{p}}$ is the injected polymer concentration in solution; and $\omega$ is the Todd-Longstaff mixing parameter.

The mixing parameter is convenient in modelling the degree of segregation between the water and the injected polymer. If $\omega=1$, then the polymer solution and water are fully mixed in each grid block. On the other hand, if $\omega=0$, then the polymer is completely segregated from the water. The Todd-Longstaff mixing parameter was specified using the TLMIXPAR keyword.

The SALTNODE keyword comprised tables of salt concentration values, each describing the nodal values for salt concentration to be used in the calculation of the polymer solution viscosity. The PLYVISCS keyword comprised tables of polymer viscosity multiplier functions, describing the effect 
on the viscosity of pure of increasing the concentration of polymer and salt in the solution.

\subsubsection{Polymer/Salt Concentrations for Mixing Calculations}

The PLYMAX keyword comprised data of maximum polymer and salt concentrations that were to be used in the mixing parameter for the calculation of the fluid component viscosities. The data contained the value of the polymer concentration in the solution which was to be used in the calculation of the maximum polymer fluid component viscosity and the value of the salt concentration which was to be used in the calculation of the maximum polymer fluid component viscosity.

\section{Results and Discussion}

Several flooding techniques were used to ascertain the effectiveness of LSW, alkaline, surfactant and polymer flooding. The production life of the reservoir was taken to be five years. The flooding process started from the first day of production beginning from January 1, 2020. The wellbore diameter was $0.5 \mathrm{~m}$, and the reservoir fluid volume rate target or upper limit was set at $100 \mathrm{sm}^{3} /$ day for both injector and producer wells. The Field Oil Efficiency (FOE), Field Oil Production Rate (FOPR) and the Water Cut (FWCT) were illustrated on a graph for each flooding process.

\subsection{Conventional Water Flooding}

Injection of water is the most common method to supplement the natural energy of the reservoir to improve oil recovery. Water injection has been used for decades to provide pressure support to the reservoir and to displace the oil. The potential benefits from waterflooding were first recognised in the 1880's and field applications were initiated in the 1930's. [19]. Today, waterflooding is the most used fluid injection process in the world. The source of water had been usually selected based on its availability and in the case of offshore oil production, sea water was the apparent choice. Little consideration was given to the salinity of the injection water.

Conventional water flooding (high salinity water flooding) was carried out in the simulation starting from the first day of production and continued for five years. Most conventional water flooding processes use sea water which has a high salt concentration. Furthermore, conventional water flooding uses a salinity concentration which is identical to the that of the formation water. In this study, it was assumed conventional water flooding had salinity of $35000 \mathrm{ppm}$ which is equal to the salinity of sea water. The results of the numerical simulation are shown in Figures 5 to 7.

Figure 5 to 7 shows the oil recovery, oil production rate and water cut for conventional water flooding from the beginning of production up until five years. From Figure 5, the oil recovery factor increases steadily until water breakthrough point is reached, which is around 550 days. As a result of the water breakthrough, the rate of oil recovery drops and ultimately reaches approximately $59.5 \%$ for the total production period. Additionally, the oil production rate is constant at roughly $100 \mathrm{sm} 3 /$ day at the onset of production for 550 days until water breakthrough occurs. Accordingly, the oil production rate sharply declines as there is influx of water into the production wells. The rate of decline slows down and becomes constant from 1000 days to the end of the production period (Figure 6). From Figure 7, there is no influx of water i.e., water cut is zero from beginning of production until water reaches breakthrough. Breakthrough point is around 550 days. When water breakthrough is reached, oil production declines as shown in Figure 6.

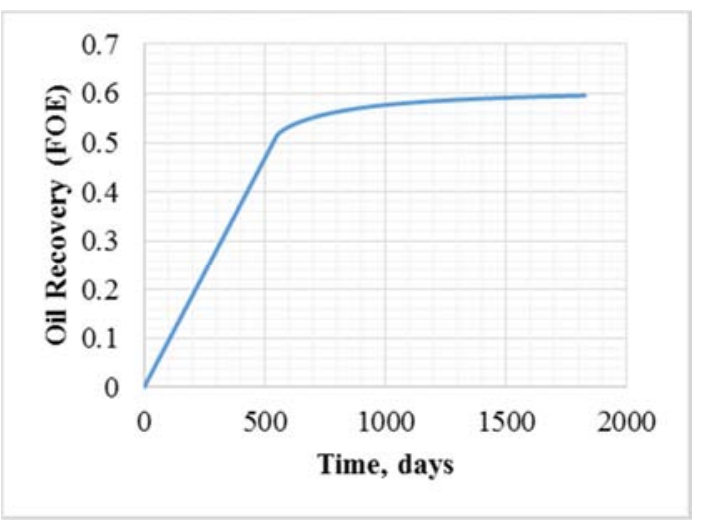

Figure 5. Oil Recovery for Conventional Water Flooding.

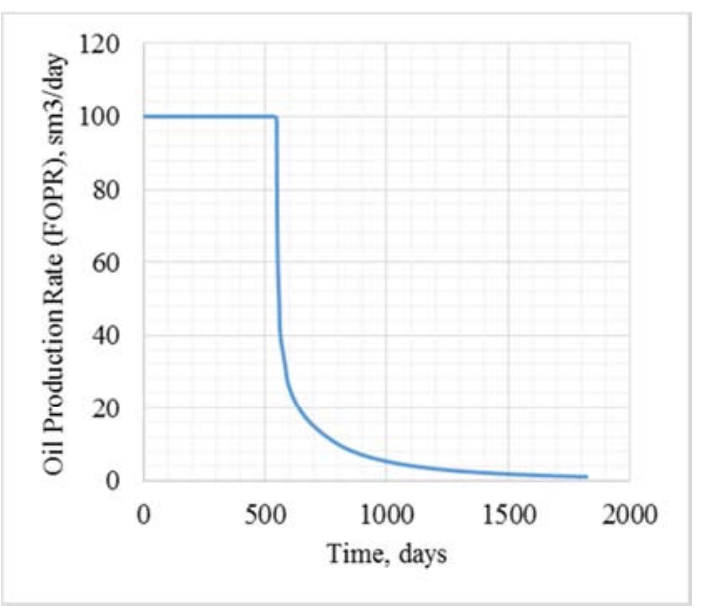

Figure 6. Oil Production Rate for Conventional Water Flooding.

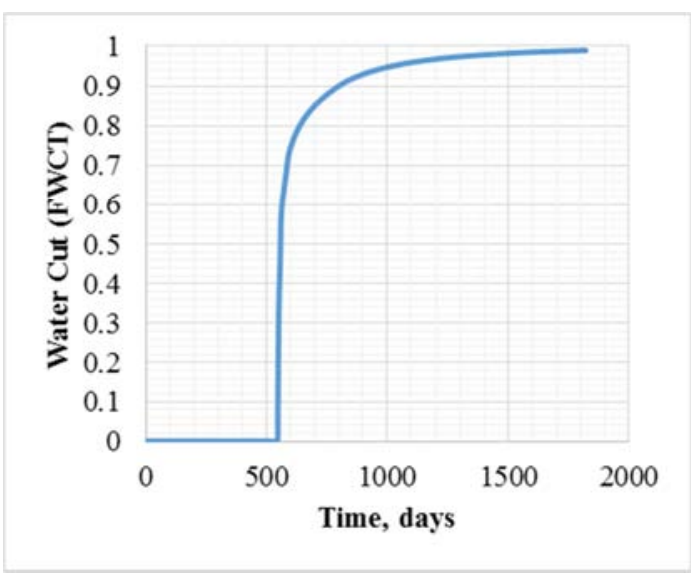

Figure 7. Water Cut for Conventional Water Flooding. 


\subsection{Low Salinity Water Flooding}

In the simulation of LSW flooding, a salinity concentration lower than that of the formation water was used. Low salinity concentration was taken to be $1000 \mathrm{ppm}$ in this study. LSW was injected into the reservoir at the start of production and continued up until five years such as the case of the conventional water flooding. The results of the simulation are illustrated Figures 8 to 10 . Figures 8 to 10 , respectively shows the oil recovery, oil production rate and water cut for LSW flooding from beginning of production up until five years. From Figure 8, oil recovery rises gradually from start of production until water breakthrough is reached in 570 days. The oil recovery does not increase as much after water breakthrough and ultimately reaches $64.1 \%$ after the production period. From Figure 9, oil production rate begins at $100 \mathrm{sm}^{3} /$ day and maintains this rate until there is influx of water into the production wells as a result of water breakthrough. The production rate sharply declines after this point. The rate of decline slows down around 1000 days and at the end of the production period, the production rate is approximately $3 \mathrm{sm}^{3} /$ day. The water cut sharply rises after water breakthrough and its value at the end of the production life is $97 \%$ (Figure 10 ).

The oil recovery result obtained from the numerical simulation agrees with the experimental work conducted by Bernard [20]. Bernard [20] studied the effect of floodwater salinity on recovery of oil from cores containing clays. The work showed that Sodium Chloride $(\mathrm{NaCl})$ brine in the range of 0 to $1 \%$ resulted in a higher oil recovery than distilled water. However, the oil recovery was mostly unaffected when the $\mathrm{NaCl}$ concentration was between 1 and $15 \%$. Additionally, Jadhunandan and Morrow [21] investigated the effect of wettability on recovery by water flooding. The authors found that altering the brine composition of the injection water affected the oil recovery. Other experimental studies have demonstrated that low salinity water flooding enhances oil recovery as compared to conventional water flooding [22, 23]. The findings by Jadhunandan and Morrow [21], Mahani et al. [22] and Erke et al. [23] also agree with the oil recovery result obtained from the numerical simulation of LSW flooding.

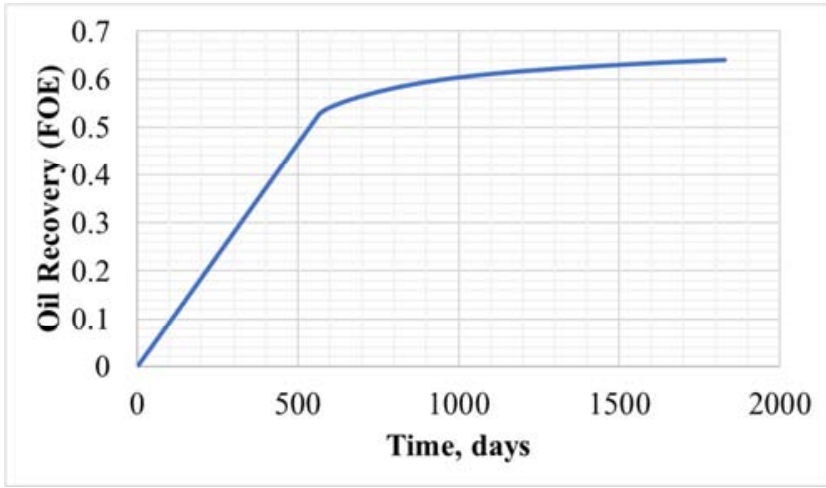

Figure 8. Oil Recovery for LSW Flooding.

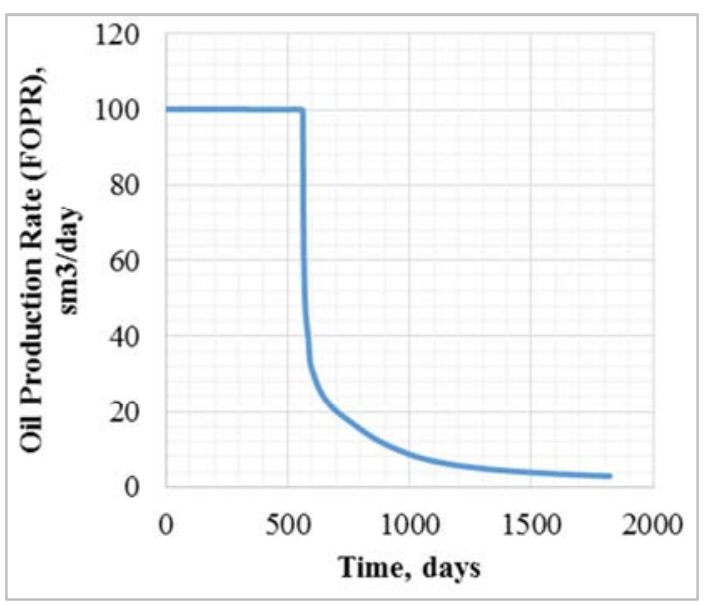

Figure 9. Oil Production Rate for LSW Flooding.

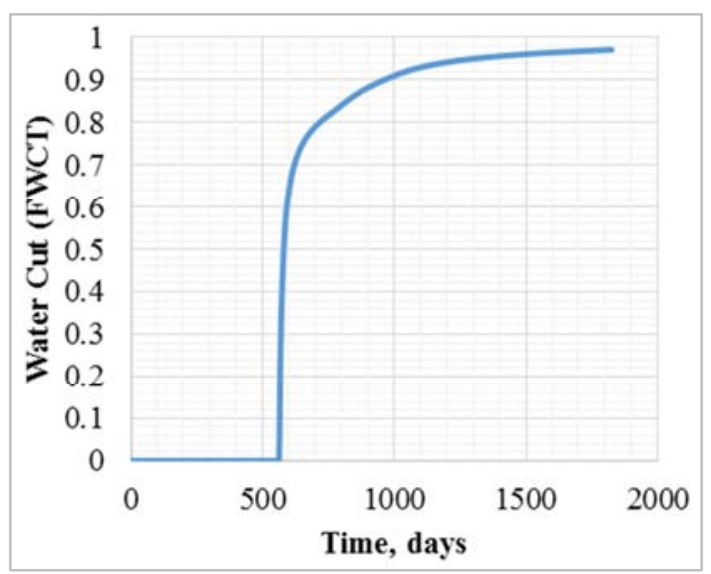

Figure 10. Water Cut for LSW Flooding.

\subsection{Low Salinity Water and Alkaline Flooding}

Simulation of the combination of LSW and alkaline flooding was done to predict the reservoir performance. The first injection phase i.e., primary injection was LSW flooding, and it was carried out from the beginning of production up until 200 days. The secondary injection phase was alkaline flooding and it started after 200 days of production and continued until the end of production life, which was five years. The salt concentration was taken to be $1000 \mathrm{ppm}$ and alkaline concentration was $3 \% \mathrm{wt}$. or $30000 \mathrm{ppm}$. The results of the numerical simulation are shown in Figures 11 to 13.

Figures 11 to 13 illustrates the oil recovery, oil production rate and water cut for combined LSW and alkaline flooding from beginning of production up until five years. The overall oil recovery was $64.1 \%$ which was higher than conventional water flooding. Nevertheless, there was not a substantial effect on oil recovery when the alkaline concentration was $3 \%$ wt. such in the case of combination with LSW flooding (Figure 11). This can be clarified by the fact that alkaline did not react with oil strongly enough to produce surfactants in situ. The oil may be said to not have contained enough naphthenic acids to interact with the alkaline. From Figure 12, the oil production rate was maintained at $100 \mathrm{sm}^{3} /$ day until water breakthrough occurred. It declined afterwards and the rate after five years 
was $3 \mathrm{sm}^{3} /$ day. The water cut from the onset of production to the point of water breakthrough was 0 . It sharply rose afterwards and the value at the end of production was $97 \%$ (Figure 13).

The oil recovery result from the numerical simulation agrees with experimental work conducted by Shaddel et al. [24]. Shaddel et al. [24] carried out core floods experiments in LSW flooding and alkaline injection to improve oil recovery. The studies demonstrated an increase in oil recovery and it was attributed to the change in the chemistry of the injected water. Moreover, other experimental works have also indicated an increase in oil recovery of combined LSW and alkaline flooding $[25,26]$ which also agree with the result obtained from the numerical simulation of LSW flooding combined with alkaline flooding.

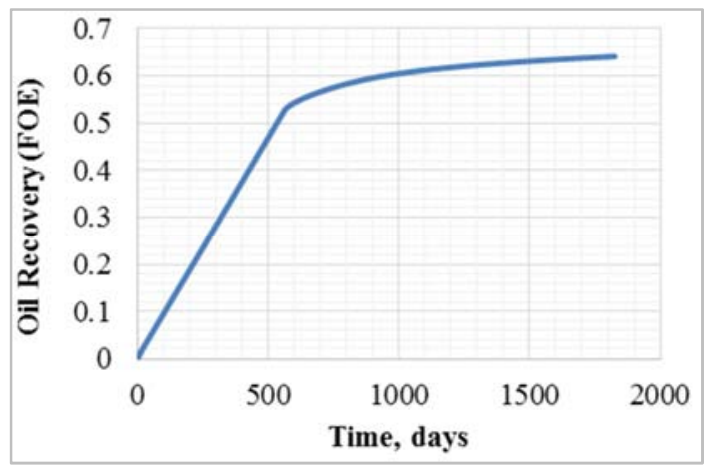

Figure 11. Oil Recovery for LSW and Alkaline Flooding.

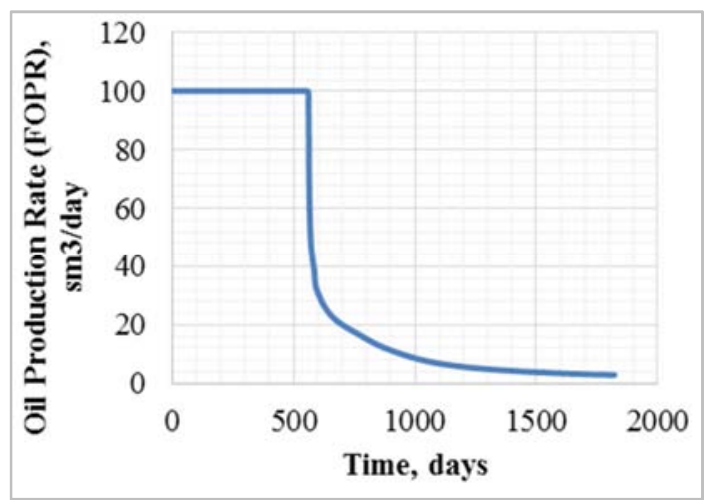

Figure 12. Oil Production Rate for LSW and Alkaline Flooding.

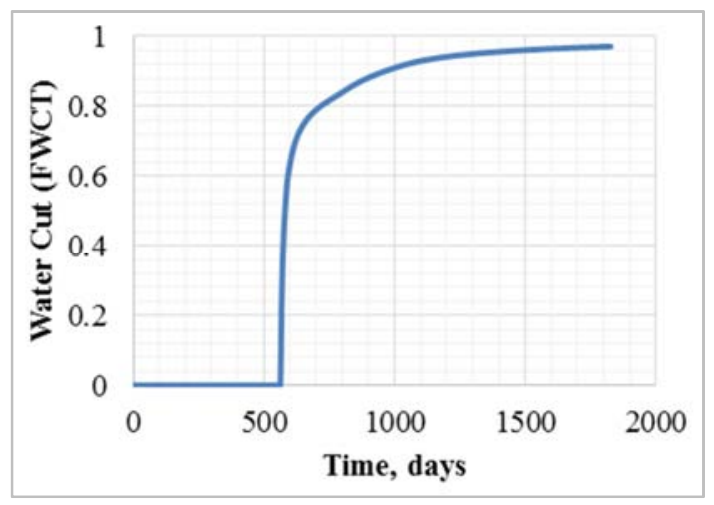

Figure 13. Water Cut for LSW and Alkaline Flooding.

\subsection{Low Salinity Water and Surfactant Flooding}

This simulation involved two injection phases. The primary injection phase was LSW flooding which was carried out from start of production to 200 days. The secondary injection was surfactant flooding which started after 200 days of production and continued until the production period i.e., five years. The salt concentration was taken to be $1000 \mathrm{ppm}$ and surfactant concentration was $2 \%$ wt. or $20000 \mathrm{ppm}$. The results of the numerical simulation are shown in Figures 14 to 16.

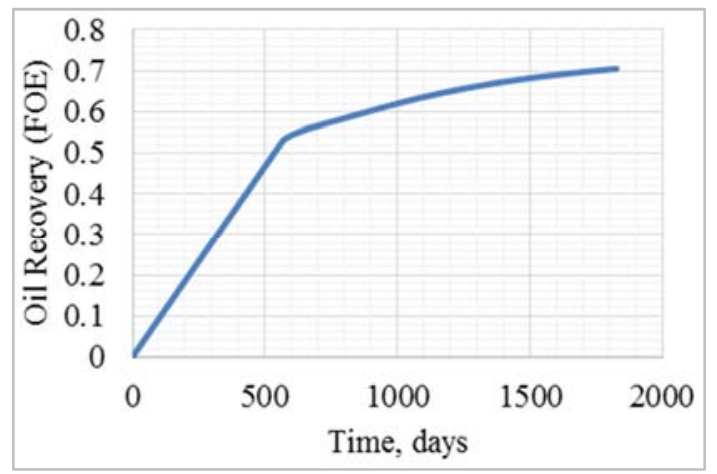

Figure 14. Oil Recovery for LSW and Surfactant Flooding.

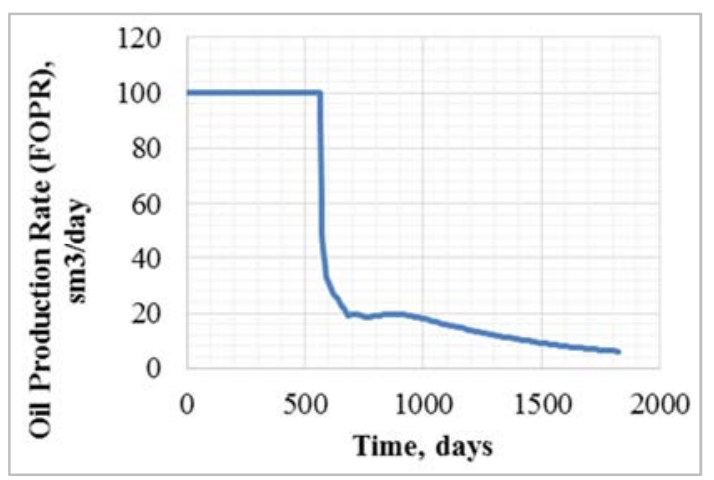

Figure 15. Oil Production Rate for LSW and Surfactant Flooding.

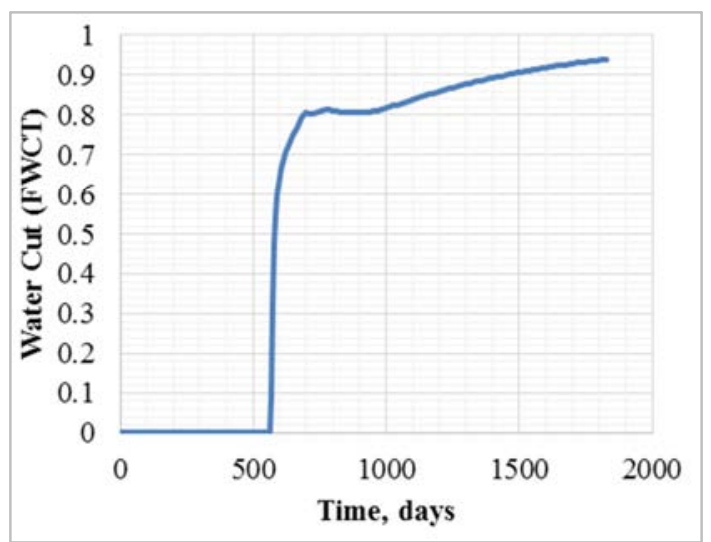

Figure 16. Water Cut for LSW and Surfactant Flooding.

Figures 14 through to 16 illustrates the oil recovery, oil production rate and water cut for combined LSW and surfactant flooding from beginning of production up until five years. From Figure 14, the oil recovery factor at the end of the production life was $70.5 \%$. The injected surfactants were 
absorbed at the interface between the oil and water, and it reduced the interfacial tension. This mobilised the oil and hence oil recovery was increased as observed. The oil production rate was kept at a constant rate of $100 \mathrm{sm}^{3} /$ day until water breakthrough occurred in 563 days. It declined after water breakthrough point and at 681 days increased due to the surfactant injection before it decreased again to the end of the production period. The flow rate at the end of production was $6 \mathrm{sm}^{3} /$ day (Figure 15). Less water was also produced at the end of five years compared to conventional water and LSW flooding. The water cut began to reduce when the surfactant came into effect to produce more oil (Figure 16).

Kakati and Sangwai [27] in their paper demonstrated the synergistic benefits of low salinity water and surfactant flooding in terms of improving oil recovery efficiency. The result from their experimental studies indicated an improved oil recovery similar to the result from the numerical simulation. Experimental works on Berea core plugs performed to study the benefits of combined LSW and surfactant flooding [28] also indicated an increase in oil recovery similar to the result obtained from the numerical simulation of LSW flooding combined with surfactant flooding.

\subsection{Low Salinity Water and Polymer Flooding}

Simulation on the combination of LSW and polymer flooding was done to predict the reservoir performance. The first injection phase i.e., primary injection was LSW flooding, and it was carried out from the beginning of production up until 200 days. The secondary injection phase was polymer flooding started after 200 days of production and continued until the end of production life, which was five years. The salt concentration in the low salinity flooding was taken to be 1 $000 \mathrm{ppm}$ and polymer concentration was $0.2 \% \mathrm{wt}$. or 2000 ppm. The results of the numerical simulation are shown in Figures 17 to 19 .

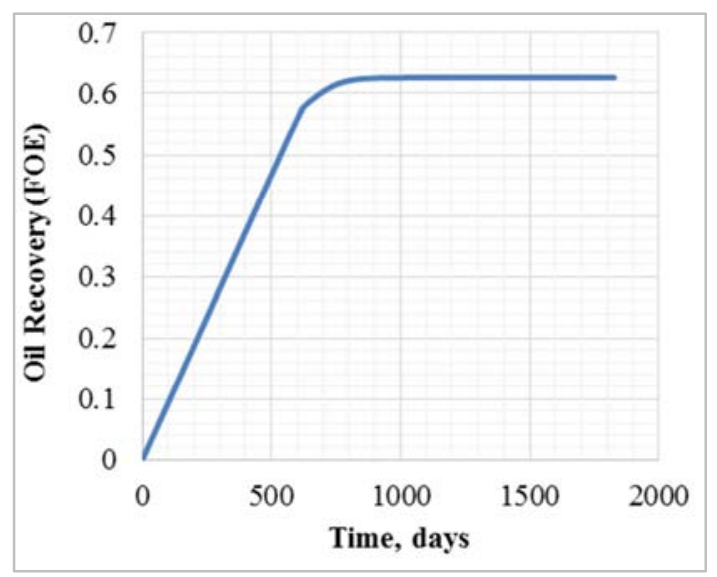

Figure 17. Oil Recovery for LSW and Polymer Flooding

Figures 17 through to 19 illustrates the oil recovery, oil production rate and water cut profile for combined LSW and polymer flooding from beginning of production up until five years. The oil recovery factor increased gradually until the time water breakthrough occurred which was about 620 days after production commenced. After breakthrough, the rate of increase dropped, and the oil recovery maintained a constant value of $62.6 \%$ to the end of production. Furthermore, oil production rate was constant until water breakthrough was reached. It sharply declined afterwards to about $40 \mathrm{sm}^{3} /$ day after 632 days of production. It then declined gradually until there was no oil produced after the production life of the reservoir.

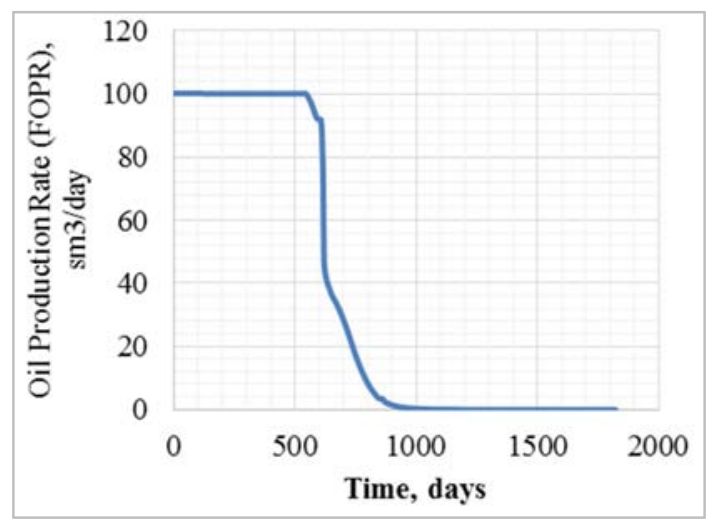

Figure 18. Oil Production Rate for LSW and Polymer Flooding.

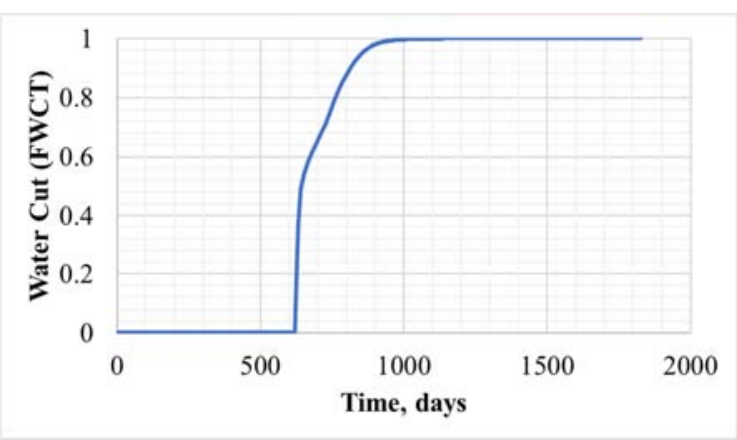

Figure 19. Water Cut for LSW and Polymer Flooding.

The oil recovery from the numerical simulation compares very well with experimental studies conducted by Vermolen et al., Alfazazi et al. and Kakati et al. [29-31]. Their studies indicated an improvement in oil recovery similar to the results obtained from the numerical simulation of LSW flooding combined with polymer flooding.

\subsection{Low Salinity Water Combined with ASP Flooding}

The numerical simulation of LSW combined with ASP flooding was investigated after studying the individual effect of low salinity flooding with each chemical flooding process. The alkaline, surfactant and polymer were assumed to be injected over the same period. The first injection phase was the LSW, which was done from start of production to 200 days. ASP flooding continued afterwards up until five years. Alkaline was injected first before surfactant and polymer were injected. This was done to prevent the adsorption of surfactants on the reservoir rock. Adsorption of surfactant reduces its effectiveness. The salt concentration was 1000 ppm. The alkaline, surfactant and polymer concentrations were $3.0 \%$ wt., $2.0 \%$ wt. and $0.2 \%$ wt., respectively. Figures 20 to 22 are the results obtained from the simulation. Figures 20 
to 22 illustrates the oil recovery, oil production rate and water cut profile for combined LSW and ASP flooding from beginning of production up until five years, respectively. The combined effect of the injected chemicals (alkaline, surfactant and polymer) in addition to LSW flooding yielded an oil recovery of $91 \%$ at the end of the production period (Figure 20). Interfacial tension reduction by the surfactants (injected and produced in situ), increase in mobility ratio by the polymer and the wettability change by the low salinity flooding all combined to mobilize the oil, thereby reducing the residual oil saturation. The time for water breakthrough was 627 days, hence more oil was produced than any other flooding processes discussed above (Figure 22). The oil production maintained a steady rate at $100 \mathrm{sm}^{3} /$ day from the onset of production until there was influx of water into the production well as a result of water breakthrough. It sharply decreased to $57 \mathrm{sm}^{3} /$ day after water breakthrough. The production rate gradually declined until 890 days; it then increased a little bit before ultimately declining to the end of the production period. The production rate at the end was 6 $\mathrm{sm}^{3} /$ day (Figure 21). It was observed that the water cut had an inverse relation to the oil production rate, meaning the water cut goes down when the injected chemicals come into effect and go up again when less oil is present (Figure 22).

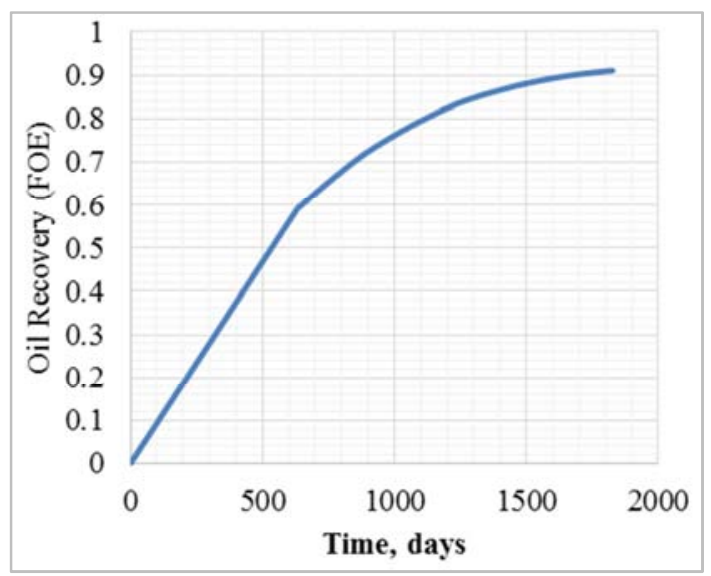

Figure 20. Oil Recovery for LSW and ASP Flooding.

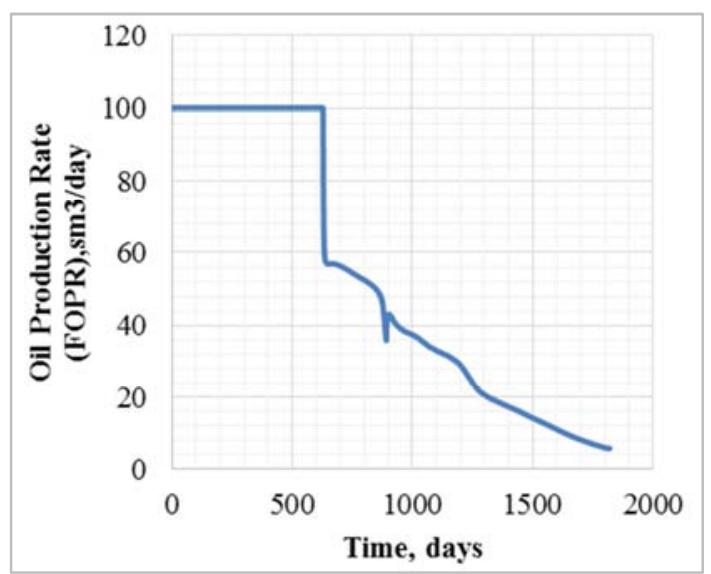

Figure 21. Oil Production Rate for LSW and ASP Flooding.

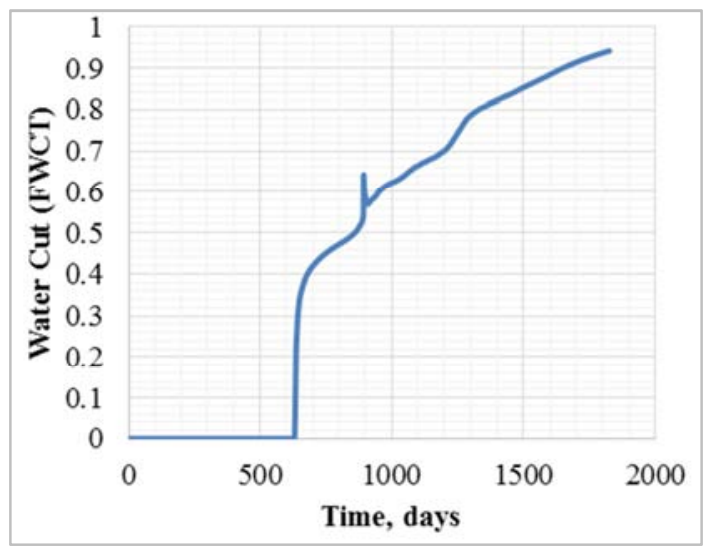

Figure 22. Water Cut for LSW and ASP Flooding.

The oil recovery from the numerical simulation compares very well with experimental studies conducted by Battistutta et al., Gregersen et al. and Novriansyah et al. [32-34]. Their findings suggested an improvement in oil recovery similar to the numerical simulation of LSW flooding combined with ASP flooding.

\section{Conclusions}

This study investigated the combination of LSW flooding and alkaline, surfactant, polymer flooding for enhanced oil recovery in a reservoir initially saturated with oil and water. A reservoir model was developed using Eclipse 100 Simulator for the study. In addition, an analytical model was developed using MATLAB. The oil recovery efficiency, oil production rate and water cut were discussed for each flooding process under the numerical simulation. The analytical modelling also discussed the fractional flow theory and the oil recovery factor for each of the flooding processes. At the end of this study, the following conclusions were drawn from the numerical simulation:

1) LSW flooding using a salt concentration of $1000 \mathrm{ppm}$ achieved a higher oil recovery than conventional (high salinity) water flooding with a salt concentration equal to that of sea water, $35000 \mathrm{ppm}$. The oil recovery for conventional water flooding was $59.5 \%$ and that of low salinity flooding was $64.1 \%$. LSW flooding, at the end of the production period also yielded a higher oil production rate and a favourable water cut than conventional water flooding. The oil production rate was $3 \mathrm{sm}^{3} /$ day and $1 \mathrm{sm}^{3} /$ day for low salinity and conventional water flooding, respectively. Additionally, there was a $1.89 \%$ decrease in water cut in LSW flooding from conventional water flooding. This was attributed to the fact that the LSW injected altered the wettability in the reservoir which released the trapped oil in the pores of the reservoir rock.

2) LSW flooding combined with each of the chemical flooding i.e., alkaline, surfactant and polymer produced a significant increase in oil recovery, oil production rate with a favourable water cut. The overall oil recovery for LSW flooding combined with alkaline, surfactant and 
polymer flooding were $64.1 \%, 70.5 \%$ and $62.6 \%$, correspondingly. This demonstrated an improvement in overall oil recovery over LSW flooding alone. This was as result of interfacial tension reduction by alkaline and surfactant, sweep efficiency increase by polymer and the wettability alteration by the reduced salt concentration.

3) The injection of alkaline, surfactant and polymer (ASP) as the same slug combined with LSW yielded an oil recovery of $91 \%$. It was the highest amongst the flooding processes that were investigated. LSW flooding combined with ASP flooding at the end of the production period also yielded the highest oil production rate and the most favourable water cut. This was attributed to the synergy of the injected chemicals as well as the wettability alteration by the LSW.

\section{References}

[1] Green, D. W. and Willhite, G. P. (2018), Enhanced Oil Recovery, SPE Textbook Series, Society of Petroleum Engineers, Richardson, Texas, 2211 pp.

[2] Behnoudfar, P., Rostami, A., and Hemmati-Sarapardeh, A. (2018), "Miscible Gas Injection", In Chap. 4 of Fundamentals of Enhanced Oil and Gas Recovery from Conventional and Unconventional Reservoirs, Bahadori, A. (ed.), Gulf Professional Publishing, pp. 101-138.

[3] Alamooti, A. M. and Malekabadi, F. K. (2018), "An Introduction to Enhanced Oil Recovery", In Chap. 1 of Fundamentals of Enhanced Oil and Gas Recovery from Conventional and Unconventional Reservoirs, Bahadori, A. (ed.), Gulf Professional Publishing, pp. 1-40.

[4] Sheng, J. J. (2014), "Critical Review of Low-salinity Waterflooding", Journal of Petroleum Science and Engineering 120, pp. 216-224.

[5] Alagic, E. and Skauge, A., (2010), "Combined Low-salinity Brine Injection and Surfactant Flooding in Mixed-wet Sandstone Cores", Energy \& Fuels, Vol. 24, No. 6, pp. 3551-3559.

[6] Wang, J., Yuan, S., Shen, P., Zhong, T. and Jia, X. (2007), Understanding of Fluid Flow Mechanism in Porous Media of EOR by ASP Flooding from Physical Modeling, Presented at International Petroleum Technology Conference, Dubai, pp. 1-8.

[7] Dang, C., Nghiem, L., Nguyen, N., Chen, Z., Yang, C. and Bae, W. (2017), "A Comprehensive Evaluation of Alkaline Polymer Surfactant Flooding and Hybrid Process for Enhanced Oil Recovery", Society of Petroleum Engineers Annual Technical Conference and Exhibition, 9-11 October, 40 pp.

[8] Mishra, S., Bera, A. and Mandal, A. (2014), "Effect of Polymer Adsorption on Permeability Reduction in Enhanced Oil Recovery", Journal of Petroleum Engineering, pp. 1-9.

[9] Khan, M. Y., Samanta, A., Ojha, K. and Mandal, A. (2009), "Design of Alkaline/Surfactant/Polymer (ASP) Slug and its Use in Enhanced Oil Recovery", Petroleum Science and Technology, the Vol. 27, No. 17, pp. 1926-1942.

[10] Anon. (2014), "Schlumberger Eclipse Reference Manual”, pp. $2-6$.
[11] Abhijit, S., Achinta, B., Keka, O., and Ajay, M. (2012), "Comparative Studies on Enhanced Oil Recovery by AlkaliSurfactant and Polymer Flooding", Journal of Petroleum Exploration and Production Technology, pp. 67-74.

[12] Anon (2021), "MRST MATLAB Reservoir Simulation Toolbox, https://www.sintef.no/projectweb/mrst/modules/mrst -core/data-sets/. Accessed: March 4, 2021.

[13] Gbadamosi, A. O., Junin, R., Manan, M. A., Agi, A. and Yusuff, A. S. (2019), "An Overview of Chemical Enhanced Oil Recovery: Recent Advances and Prospects", International Nano Letters 9, pp. 171-202.

[14] Sheng, J. J. (2011), Modern Chemical Enhanced Oil Recovery Theory and Practice, Gulf Professional Publishing, Burlington, USA, 617 pp.

[15] Terry, E. R. (2001), "Enhanced Oil Recovery", Encyclopaedia of Physical Science and Technology, 3rd edition, Vol. 18, Meyers, A. R. (ed.), Academic Press, pp. 503-518.

[16] Chen, Y., He, H., Yu, Q., Liu, H., Chen, L., Ma, X., and Liu, W. (2021), "Insights into Enhanced Oil Recovery by Polymer-Viscosity Reducing Surfactant Combination Flooding in Conventional Heavy Oil Reservoir", Geofluids, pp. 1-12.

[17] Li, X., Zhang, F. and Liu, G. (2021), "Review on Polymer Flooding Technology", IOP Conference Series: Earth and Environmental Science 675, pp. 1-6.

[18] Alsofi, A. M. and Blunt, M. J. (2014), "Polymer Flooding Design and Optimization under Economic Uncertainty", Journal of Petroleum Science and Engineering, Vol., 124, pp. 46-59.

[19] Smith, J. T., and Cobb W. M. (1997), "Waterflooding", Midwest Office of the Petroleum Technology Transfer Council, pp. 1-4.

[20] Bernard, G. G. (1967), "Effect of Floodwater Salinity on Recovery of Oil from Cores Containing Clays", Society of Petroleum Engineers California Regional Meeting, Los Angeles, California, October 1967, 8 pp.

[21] Jadhunandan, P. and Morrow, N. R. (1995), "Effect of Wettability on Waterflood Recovery for Crude Oil/Brine/Rock Systems", SPE Reservoir Engineering, pp. 40-46.

[22] Mahani, H., Sorop, T., Ligthelm, D. J., Brooks, D., Vledder, P., Mozahem, F. and Ali, Y. (2011), "Analysis of Field Responses to Low-Salinity Waterflooding in Secondary and Tertiary Mode in Syria", Paper Presented at the SPE EUROPEC/EAGE Annual Conference and Exhibition, Vienna, Austria, May 2011, $14 \mathrm{pp}$.

[23] Erke, S. I., Volokitin, Y. E., Edelman, I. Y., Karpan, V. M., Nasralla, R. A., Bondar, M. Y., Mikhaylenko, E. E. and Evseeva, M. (2016), "Low Salinity Flooding Trial at West Salym Field", Society of Petroleum Engineers Improved Oil Recovery Conference, Tulsa, Oklahoma, USA, April 2016, 11 $\mathrm{pp}$.

[24] Shaddel, S., Hemmati, M., Zamanian, E. and Moharrami, N. N. (2013), "Low Salinity Water Flooding and Combination of Low Salinity Water Flooding with Surfactant and Alkaline Injection to Improve Oil Recovery-Core Flooding Experiments", International Journal of Petroleum and Geoscience Engineering, Vol. 1, No. 2, pp. 91-98. 
[25] Assef, Y., Arab, D. and Pourafshary, P. (2014), "Application of Nanofluid to Control Fines Migration to Improve the Performance of Low Salinity Water Flooding and Alkaline Flooding", Journal of Petroleum Science and Engineering, Vol. 124, pp 331-340.

[26] Al-Saedi, H. N., Flori, R. E., Al-Jaberi, S. K. and Al-Bazzaz, W (2020), "Low-Salinity Water, $\mathrm{CO}_{2}$, Alkaline, and Surfactant EOR Methods Applied to Heavy Oil in Sandstone Cores", SPE Journal, Vol. 25, No. 4, pp. 1729-1744.

[27] Kakati, A. and Sangwai, J. S. (2021), "Low Salinity Surfactant Flooding: Role of Surfactant and Salt", Surfactants in Upstream E\&P, pp. 225-243.

[28] Araz, A. and Kamyabi, F. (2020), "Experimental study of Combined Low Salinity and Surfactant Flooding Effect on Oil Recovery", Oil and Gas Science and Technology-Rev. IFP Energies Nouvelles, Vol. 76, No. 4, 9 pp.

[29] Vermolen, E. C. M., Almada, M. P., Wassing, B. M., Ligthelm, D. J. and Masalmeh, S. K. (2014), "Low-Salinity Polymer Flooding: Improving Polymer Flooding Technical Feasibility and Economics by Using Low-Salinity Make-up Brine", International Petroleum Technology Conference, 15 pp.
[30] Alfazazi, U., AlAmeri, W. and Hashmet, M. R. (2019), "Experimental Investigation of Polymer Flooding with Low-Salinity Preconditioning of High TemperatureHigh-Salinity Carbonate Reservoir", Journal of Petroleum Exploration and Production Technology, Vol. 9, pp. 1517-1530.

[31] Kakati, A., Kumar, G. and Sangwai. J. S. (2020), "Low Salinity Polymer Flooding: Effect on Polymer Rheology, Injectivity, Retention, and Oil Recovery Efficiency", Energy Fuels, Vol. 34 No. 5, pp. 5715-5732.

[32] Battistutta, E., Van Kuijk, S. R., Groen, K. V. and Zitha, P. L. (2015), "Alkaline-Surfactant-Polymer (ASP) Flooding of Crude Oil at Under-Optimum Salinity Conditions", SPE Asia pacific Enhanced Oil Recovery Conference, 20 pp.

[33] Novriansyah, A., Bae, W., Park, C., Permadi, A. K. and Riswati, S. S. (2020), "Optimal Design of AlkalineSurfactant-Polymer Flooding under Low Salinity Environment", Polymers 2020, Vol. 12, No. 3, pp. 626.

[34] Gregersen, C. S., Kazempour, M. and Alvarado, M. (2013), "ASP Design for the Minnelusa Formation under Low-Salinity Conditions: Impacts of Anhydrite on ASP Performance", Fuel, Vol. 105, pp. 368-382. 